\title{
Analysis of the Essential Oil of Dipsacus japonicus Flowering Aerial Parts and its Insecticidal Activity against Sitophilus zeamais and Tribolium castaneum
}

\author{
Zhi Long Liu ${ }^{\mathrm{a}, *}$, Guo Hua Jiang ${ }^{\mathrm{b}}$, Ligang Zhou ${ }^{\mathrm{c}}$, and Qi Zhi Liu \\ a Department of Entomology, China Agricultural University, \\ 2 Yuanmingyuan West Road, Haidian District, Beijing 100193, China. \\ Fax: 86-10-62732800. E-mail: zhilongliu@cau.edu.cn \\ b Analytic and Testing Center, Beijing Normal University, Haidian District, \\ Beijing 100875, China \\ c Department of Plant Pathology, China Agricultural University, \\ 2 Yuanmingyuan West Road, Haidian District, Beijing 100193, China \\ * Author for correspondence and reprint requests \\ Z. Naturforsch. 68c, 13-18 (2013); received February 12/October 30, 2012
}

\begin{abstract}
Water-distilled essential oil from the aerial parts of Dipsacus japonicus Miq. (Dipsacaceae) at the flowering stage was analysed by gas chromatography-mass spectrometry (GC-MS). Forty-six compounds, accounting for $96.76 \%$ of the total oil, were identified and the main compounds of the essential oil were linalool $(11.78 \%)$, trans-geraniol $(8.58 \%), 1,8$-cineole (7.91\%), $\beta$-caryophyllene (5.58\%), $\alpha$-terpineol (5.32\%), $\beta$-selinene $(5.15 \%)$, and spathulenol $(5.04 \%)$. The essential oil of $D$. japonicus possessed contact toxicity against two grain storage insects, Sitophilus zeamais and Tribolium castaneum adults, with $\mathrm{LD}_{50}$ values of $18.32 \mu \mathrm{g} /$ adult and $13.45 \mu \mathrm{g} /$ adult, respectively. The essential oil of D. japonicus also exhibited pronounced fumigant toxicity against $S$. zeamais $\left(\mathrm{LC}_{50}=10.11 \mathrm{mg} / \mathrm{l}\right.$ air $)$ and $T$. castaneum adults $\left(\mathrm{LC}_{50}=5.26 \mathrm{mg} / \mathrm{l}\right.$ air $)$. Of the three major compounds, 1,8-cineole exhibited stronger fumigant toxicity than the crude essential oil against $S$. zeamais and $T$. castaneum adults with $\mathrm{LC}_{50}$ values of $2.96 \mathrm{mg} / \mathrm{l}$ air and $4.86 \mathrm{mg} / \mathrm{l}$ air, respectively.
\end{abstract}

Key words: Dipsacus japonicus, Essential Oil, Insecticidal Activity

\section{Introduction}

Botanical pesticides have the advantage of providing novel modes of action against insects that can reduce the risk of cross-resistance as well as offering new leads for the design of targetspecific molecules. During a screening program for new agrochemicals from Chinese medicinal herbs and local wild plants, the essential oil of Dipsacus japonicus Miq. (family: Dipsacaceae) flowering aerial parts was found to possess insecticidal activity against the maize weevil (Sitophilus zeamais Motsch.) and the red flour beetle (Tribolium castaneum Herbst). S. zeamais and T. castaneum are two serious pests of stored grains worldwide (Liu and Ho, 1999). Infestations not only cause significant losses due to the consumption of grains, they also result in elevated temperature and moisture conditions that lead to an accelerated growth of molds, including toxic species (Magan et al., 2003). Currently, control of stored-product insects relies heavily on the use of synthetic insecticides and fumigants. However, repeated use of synthetic fumigants for decades has led to resurgence of stored-product insect pests, sometimes resulting in the development of resistance, and had undesirable effects on non-target organisms (Zettler and Arthur, 2000). These problems have highlighted the need to develop new types of selective insect control alternatives with fumigant action. Plant essential oils and their components have been shown to possess potential to be developed as new fumigants, and they may have the advantage over conventional fumigants in terms of low mammalian toxicity, rapid degradation, and local availability (Isman, 2006; Rajendran and Srianjini, 2008).

D. japonicus is a perennial herb, growing up to $1.5 \mathrm{~m}$, and is mainly distributed in Central and Northern China as well as Japan and Korea (Flora of China Editorial Board, 1986). Dried roots of D. japonicus were used as Chinese medicinal herb, Dipsaci Radix, in the past (Jiangsu 
New Medical College, 1977). But now, tap roots of $D$. asperoides are exclusively used as medicine (Dipsaci Radix), and D. asperoides is regarded an adulterant (Chinese Pharmacopoeia Commission, 2010). Several studies on chemical constituents of $D$. japonicus have been reported, and several saponins, triterpenoid glycosides, iridoid and bisiridoid glycosides have been isolated (Wei et al., 1995, 1998; Trinh et al., 1999, 2002; Miao et al., 2000a, b). However, a literature survey has shown that there is no report on the chemical composition of the essential oil derived from D. japonicus, and the insecticidal activity of this oil against stored-product insects has not been determined. The present investigation consisted of two parts: determination of the chemical composition of the essential oil of $D$. japonicus flowering aerial parts and evaluation of the essential oil as insecticide/ fumigant for the control of the stored-product insect pests.

\section{Material and Methods}

\section{Plant material}

The flowering aerial parts of D. japonicus were collected in August 2009 from Xiaolongmen National Forest Park $\left(39.48^{\circ} \mathrm{N}, 115.25^{\circ} \mathrm{E}\right)$, Mentougou District, Beijing, China. The samples were air-dried and identified by Dr. Q. R. Liu (College of Life Sciences, Beijing Normal University, Beijing, China). A voucher specimen (ENTCAUDipsacaceae-10002) was deposited at the Department of Entomology, China Agricultural University, Beijing, China. The samples were ground to a powder using a grinding mill (Retsch, Haan, Germany). A $600-\mathrm{g}$ portion of powder was dispersed in $1,800 \mathrm{ml}$ of distilled water and soaked for $3 \mathrm{~h}$. The mixture was then boiled in a round-bottom flask and steam-distilled for 6-8 h. Separation of the essential oil from the aqueous layer was done in a separatory funnel, using the non-polar solvent $n$-hexane. The solvent was evaporated using a vacuum rotary evaporator (Büchi rotavapor R-124; Flawil, Switzerland). The resulting sample was dried over anhydrous $\mathrm{Na}_{2} \mathrm{SO}_{4}$ and kept at $4{ }^{\circ} \mathrm{C}$ for subsequent experiments. Linalool (98\%), 1,8-cineole (98\%), and trans-geraniol (98\%) were purchased from Sigma-Aldrich Chemical Co. (St. Louis, MO, USA).

\section{Insects}

Maize weevils (S. zeamais) and red flour beetles ( $T$. castaneum) were obtained from laboratory cultures maintained in the dark in incubators at $29-30{ }^{\circ} \mathrm{C}$ and $70-80 \%$ relative humidity. The red flour beetles were reared on wheat flour mixed with yeast $(10: 1, \mathrm{w} / \mathrm{w})$, while maize weevils were reared on whole wheat grains at $12-13 \%$ moisture content in glass jars (diameter, $85 \mathrm{~mm}$; height, $130 \mathrm{~mm}$ ). About one-week-old, unsexed adult weevils/beetles were used in all experiments. All containers housing insects and the Petri dishes used in experiments were made escape-proof with a coating of polytetrafluoroethylene (Fluon, Blades Biological, Edenbridge, UK).

\section{Gas chromatography-mass spectrometry (GC-MS)}

The essential oil of D. japonicus was subjected to GC-MS analysis on an Agilent (Santa Clara, CA, USA) system consisting of a model $6890 \mathrm{~N}$ gas chromatograph, a model $5973 \mathrm{~N}$ mass selective detector (EIMS; electron energy, $70 \mathrm{eV}$ ), and an Agilent ChemStation data system. The GC column was an HP-5ms (Hewlett Packard, Santa Clara, CA, USA) fused silica capillary with a $5 \%$ phenyl-methylpolysiloxane stationary phase, a film thickness of $0.25 \mu \mathrm{m}$, a length of $30 \mathrm{~m}$, and an internal diameter of $0.25 \mathrm{~mm}$. The GC settings were as follows: The initial oven temperature was held at $60^{\circ} \mathrm{C}$ for $1 \mathrm{~min}$ and ramped at $10^{\circ} \mathrm{C} /$ min to $180{ }^{\circ} \mathrm{C}$, held for $1 \mathrm{~min}$, and then ramped at $20^{\circ} \mathrm{C} / \mathrm{min}$ to $280{ }^{\circ} \mathrm{C}$ and held for $15 \mathrm{~min}$. The injector temperature was maintained at $270^{\circ} \mathrm{C}$. The sample $(1 \mu \mathrm{l})$ was injected neat, with a split ratio of 1:10. The carrier gas was helium at a flow rate of $1.0 \mathrm{ml} / \mathrm{min}$. Spectra were scanned from $\mathrm{m} / \mathrm{z} 20$ to 550 at 2 scans/s. Most constituents were identified by gas chromatography by comparison of their retention indices with those found in the literature or with those of authentic compounds available in our laboratories. The retention indices were determined in relation to a homologous series of $n$-alkanes $\left(\mathrm{C}_{8}-\mathrm{C}_{24}\right)$ under the same operating conditions. Further identification was made by comparison of their mass spectra with those stored in NIST 08 and Wiley 275 libraries or with mass spectra available in the literature (Adams, 2007). Component relative percentages were calculated based on the normalization method without using correction factors. 


\section{Contact toxicity by topical application}

The contact toxicity of the essential oil of $D$. japonicus and its major constituents against $S$. zeamais and T. castaneum adults was measured as described by Liu and Ho (1999). Rangefinding studies were run to determine the appropriate testing concentrations of the essential oil/compounds. A serial dilution of the essential oil/compounds (6 concentrations) was prepared in $n$-hexane. Aliquots of $0.5 \mu \mathrm{l} /$ insect were topically applied dorsally to the thorax of the insects, using a Burkard Arnold microapplicator (Burkard Scientific Supply, Rickmansworth, England). Controls were determined using $0.5 \mu \mathrm{l}$ $n$-hexane/insect. Ten insects were used for each concentration and control, and the experiment was replicated six times. Both the treated and control insects were then transferred into glass vials (10 insects/vial) containing culture medium and kept in incubators at $29-30{ }^{\circ} \mathrm{C}$ and $70-80 \%$ relative humidity. Mortality of insects was observed after $24 \mathrm{~h}$. The observed mortality data were corrected for control mortality using Abbott's formula. Results from all replicates were subjected to probit analysis using the PriProbit Program V1.6.3 to determine $\mathrm{LD}_{50}$ values (Sakuma, 1998).

\section{Fumigant toxicity bioassay}

Range-finding studies were run to determine the appropriate testing concentrations of D. japonicus essential oil and its constituents. A Whatman filter paper (diameter, $2.0 \mathrm{~cm}$ ) was placed on the underside of the screw cap of a glass vial (diameter, $2.5 \mathrm{~cm}$; height, $5.5 \mathrm{~cm}$; volume, $24 \mathrm{ml}$ ). Ten $\mu \mathrm{l}$ of the essential oil/compounds (6 concentrations) were added to the filter paper. The solvent was allowed to evaporate for $15 \mathrm{~s}$ before the cap was placed tightly on the glass vial (with 10 unsexed insects) to form a sealed chamber. The vials were incubated at $27-29^{\circ} \mathrm{C}$ and $70-80 \%$ relative humidity for $24 \mathrm{~h}$. Mortality of insects was observed and corrected for control mortality using Abbott's formula. The results from all replicates were subjected to probit analysis using the PriProbit Program V1.6.3 to determine LC $_{50}$ values (Sakuma, 1998).

\section{Results and Discussions}

Essential oil analysis

The yield of the yellow essential oil from $D$. japonicus flowering aerial parts was $0.12 \%(\mathrm{v} / \mathrm{w})$, and the density of the concentrated essential oil was $0.83 \mathrm{~g} / \mathrm{ml}$. A total of 46 compounds of the essential oil were identified, accounting to $96.76 \%$ of the total oil. The principal compounds in the essential oil were linalool $(11.78 \%)$, trans-geraniol $(8.58 \%), 1,8$-cineole $(7.91 \%), \beta$-caryophyllene $(5.58 \%), \alpha$-terpineol $(5.32 \%), \beta$-selinene $(5.15 \%)$, and spathulenol $(5.04 \%)$ (Table I). Monoterpenoids represented 21 of the 46 compounds, corresponding to $58.70 \%$ of the whole oil, while 17 of the 46 constituents were sesquiterpenoids (34.35\% of the crude essential oil).

\section{Insecticidal activity}

The essential oil of D. japonicus flowering aerial parts possessed contact toxicity against $S$. zeamais and T. castaneum adults with $\mathrm{LD}_{50}$ values of $18.32 \mu \mathrm{g} /$ adult and $13.45 \mu \mathrm{g} /$ adult, respectively (Table II). Compared with the positive control, pyrethrum extract (25\% pyrethrine I and pyrethrine II), the essential oil of D. japonicus was 4 and 37 times less acutely toxic against the two species of grain storage insects. The pyrethrum extract had an acute toxicity to $S$. zeamais and $T$. castaneum with $\mathrm{LD}_{50}$ values of $4.29 \mu \mathrm{g} / \mathrm{adult}$ and $0.36 \mu \mathrm{g} /$ adult, respectively (Liu et al., 2010).

The essential oil of $D$. japonicus also exhibited stronger fumigant toxicity against $T$. castaneum adults $\left(\mathrm{LC}_{50}=5.26 \mathrm{mg} / \mathrm{l}\right.$ air $)$ than $S$. zeamais adults $\left(\mathrm{LC}_{50}=10.11 \mathrm{mg} / \mathrm{l}\right.$ air) (Table III). The commercial grain fumigant methyl bromide $(\mathrm{MeBr})$ was reported to have fumigant activity against $S$. zeamais and T. castaneum adults with $\mathrm{LC}_{50}$ values of $0.67 \mathrm{mg} / \mathrm{l}$ air and $1.75 \mathrm{mg} / \mathrm{l}$ air, respectively (Liu and Ho, 1999), thus the essential oil of $D$. japonicus was 15 and 3 times less toxic to $S$. zeamais and T. castaneum, respectively. However, considering that the commercial fumigants are synthetic insecticides, the fumigant activity of the essential oil of $D$. japonicus flowering aerial parts is quite promising. Moreover, compared with the other essential oils in previous studies, the essential oil of $D$. japonicus flowering aerial parts exhibited stronger or the same level of fumigant toxicity against the maize weevils, e.g. essential oils of Artemisia lavandulaefolia $\left(\mathrm{LC}_{50}=\right.$ 
Table I. Chemical constituents of the essential oil derived from Dipsacus japonicus flowering aerial parts.

\begin{tabular}{|c|c|c|c|}
\hline Peak no. & Compound & RI* & Content (\%) \\
\hline 1 & $\alpha$-Pinene & 931 & 3.57 \\
\hline 2 & $\beta$-Pinene & 974 & 0.28 \\
\hline 3 & $\beta$-Myrcene & 991 & 0.91 \\
\hline 4 & $\delta$-3-Carene & 1007 & 1.06 \\
\hline 5 & $a$-Terpinene & 1017 & 0.67 \\
\hline 6 & $p$-Cymene & 1025 & 0.34 \\
\hline 7 & 1,8-Cineole & 1032 & 7.91 \\
\hline 8 & $\gamma$-Terpinene & 1059 & 0.78 \\
\hline 9 & Terpinolen & 1089 & 0.56 \\
\hline 10 & Linalool & 1094 & 11.78 \\
\hline 11 & Phenylethyl alcohol & 1116 & 1.11 \\
\hline 12 & Camphor & 1146 & 0.45 \\
\hline 13 & Borneol & 1174 & 1.21 \\
\hline 14 & 4-Terpineol & 1179 & 2.93 \\
\hline 15 & p-Cymen-8-ol & 1182 & 0.96 \\
\hline 16 & $\alpha$-Terpineol & 1189 & 5.32 \\
\hline 17 & Carvone & 1238 & 1.38 \\
\hline 18 & trans-Geraniol & 1252 & 8.58 \\
\hline 19 & Linalool acetate & 1254 & 1.28 \\
\hline 20 & Bornyl acetate & 1287 & 1.66 \\
\hline 21 & Thymol & 1292 & 0.69 \\
\hline 22 & 4-Vinylguaiacol & 1311 & 0.25 \\
\hline 23 & $\alpha$-Cubebene & 1350 & 2.66 \\
\hline 24 & Citronellol acetate & 1354 & 0.01 \\
\hline 25 & Eugenol & 1356 & 0.82 \\
\hline 26 & $\alpha$-Copaene & 1375 & 1.02 \\
\hline 27 & $\beta$-Elemene & 1394 & 2.39 \\
\hline 28 & $\alpha$-Gurjunene & 1406 & 0.78 \\
\hline 29 & $\beta$-Caryophyllene & 1420 & 5.58 \\
\hline 30 & trans- $\alpha$-Ionone & 1426 & 0.47 \\
\hline 31 & Dihydro- $\beta$-ionone & 1433 & 1.49 \\
\hline 32 & $(Z)$ - $\beta$-Farnesene & 1438 & 0.43 \\
\hline 33 & Geranyl acetone & 1458 & 3.88 \\
\hline 34 & $\gamma$-Selinene & 1470 & 0.99 \\
\hline 35 & $\gamma$-Gurjunene & 1473 & 1.26 \\
\hline 36 & $\beta$-Selinene & 1489 & 5.15 \\
\hline 37 & $\gamma$-Cadinene & 1513 & 1.56 \\
\hline 38 & Dihydroactinolide & 1525 & 0.57 \\
\hline 39 & $\alpha$-Calacorene & 1546 & 0.76 \\
\hline 40 & Ledol & 1562 & 0.69 \\
\hline 41 & Spathulenol & 1578 & 5.04 \\
\hline 42 & Globulol & 1582 & 0.01 \\
\hline 43 & Caryophyllene oxide & 1583 & 2.79 \\
\hline 44 & $\beta$-Eudesmol & 1648 & 2.43 \\
\hline 45 & $\alpha$-Cadinol & 1654 & 0.17 \\
\hline \multirow[t]{5}{*}{46} & $\beta$-Bisabolol & 1673 & 0.65 \\
\hline & Total & & 96.76 \\
\hline & Monoterpenoids & & 58.70 \\
\hline & Sesquiterpenoids & & 34.35 \\
\hline & Others & & 4.71 \\
\hline
\end{tabular}

* RI, retention index as determined on an HP-5ms column using a homologous series of $n$-alkanes.
$11.2 \mathrm{mg} / \mathrm{l}$ air; Liu et al., 2010), A. vestita $\left(\mathrm{LC}_{50}=\right.$ $13.42 \mathrm{mg} / \mathrm{l}$ air; Chu et al., 2010a), Illicium simonsii $\left(\mathrm{LC}_{50}=14.95 \mathrm{mg} / \mathrm{l}\right.$ air; Chu et al., 2010b), A. sieversiana $\left(\mathrm{LC}_{50}=15.0 \mathrm{mg} / \mathrm{l}\right.$ air; Liu et al., 2010), and Kadsura heteroclita $\left(\mathrm{LC}_{50}=14.01 \mathrm{mg} / \mathrm{l}\right.$ air; $\mathrm{Li}$ et al., 2011). Compared with the other essential oils in the literature, the essential oil of D. japonicus possessed stronger fumigant toxicity against T. castaneum adults, e.g. essential oils of Citrus reticulata $\left(\mathrm{LC}_{50}=19.47 \mu \mathrm{l} / \mathrm{l}\right.$ air $)$, Schinus terebenthifolius $\left(\mathrm{LC}_{50}=20.50 \mu \mathrm{l} / \mathrm{l}\right.$ air; Mohamed and Abdelgaleil, 2008), Perovskia abrotanoides $\left(\mathrm{LC}_{50}=\right.$ $11.39 \mu \mathrm{l} / \mathrm{l}$ air; Arabi et al., 2008), and Drimys winteri $\left(\mathrm{LC}_{50}=9.0-10.5 \mu \mathrm{l} / 1\right.$ air; Zapata and Smagghe, 2010), but was lesser toxic than the essential oil of Laurelia sempervirens $\left(\mathrm{LC}_{50}=1.6-1.7 \mu \mathrm{l} / 1\right.$ air; Zapata and Smagghe, 2010).

The three main constituents of D. japonicus essential oil, viz. 1,8-cineole, trans-geraniol, and linalool, exhibited contact toxicity against the two grain storage insects $(16.34 \mu \mathrm{g} / \mathrm{adult}$, $15.11 \mu \mathrm{g} / \mathrm{adult}$, and $24.88 \mu \mathrm{g} / \mathrm{adult}$ for $S$. zeamais, respectively, and $12.67 \mathrm{mg} /$ adult, $21.34 \mathrm{mg}$ /adult, and $8.12 \mathrm{mg} /$ adult for $T$. castaneum, respectively) (Table II). Among the three compounds, 1,8-cineole possessed strongest fumigant toxicity against $S$. zeamais and $T$. castaneum adults with $\mathrm{LC}_{50}$ values of $2.96 \mathrm{mg} / \mathrm{l}$ air and $4.86 \mathrm{mg} / \mathrm{l}$ air, respectively, while the two other compounds were as active or less active than the crude essential oil. It is suggested that the fumigant toxicity of the essential oil may mainly be attributed to 1,8-cineole, because it showed stronger fumigant toxicity than the crude essential oil (no overlap in $95 \%$ confidence limits) (Table II). Moreover, in previous studies, 1,8-cineole was found to exhibit fumigant toxicity against $T$. castaneum adults with $\mathrm{LC}_{50}$ values of $41 \mu \mathrm{l} / \mathrm{l}$ air (Suthisut et al., 2011), $15.3 \mu \mathrm{l} / \mathrm{l}$ air (Lee et al., 2004), and $1.52 \mathrm{mg} / \mathrm{l}$ air (Tripathi et al., 2001), respectively. 1,8-Cineole also possessed fumigant toxicity against $S$. zeamais adults with an $\mathrm{LC}_{50}$ value of $2.96 \mathrm{mg} / \mathrm{l}$ air (Liu and $\mathrm{Du}, 2011)$. It also exhibited fumigant toxicity against several other stored-product insects and cockroaches as well as mosquitoes, e.g. the rice weevil $\left(S\right.$. oryzae; $\mathrm{LC}_{50}=22.8 \mu \mathrm{l} / \mathrm{l}$ air) and the lesser grain borer (Rhyzopertha dominica; $\mathrm{LC}_{50}=9.5 \mu \mathrm{l} / \mathrm{l}$ air) (Lee et al., 2004).

The above findings suggest that the essential oil of D. japonicus flowering aerial parts can play an important role in stored-grain protection and 
Table II. Contact toxicity of the essential oil of D. japonicus and its main compounds against S. zeamais (SZ) and T. castaneum (TC) adults.

\begin{tabular}{lllcccc}
\hline Insect & Treatment & $\begin{array}{l}\text { Content } \\
(\%)\end{array}$ & $\begin{array}{l}\mathrm{LD}_{50} \\
{[\mu \mathrm{g} / \text { adult }]}\end{array}$ & $95 \%$ FL & Slope $\pm \mathrm{SE}$ & $\begin{array}{l}\text { Chi square } \\
\left(\chi^{2}\right)\end{array}$ \\
\hline \multirow{4}{*}{$\mathrm{SZ}$} & Essential oil & $5.31-30.00$ & 18.32 & $16.47-20.36$ & $5.89 \pm 0.86$ & 23.8 \\
& 1,8-Cineole & $7.43-28.57$ & 16.34 & $14.87-17.76$ & $2.71 \pm 0.27$ & 15.49 \\
& trans-Geraniol & $1.81-28.57$ & 15.11 & $13.85-16.45$ & $4.87 \pm 0.4$ & 14.56 \\
& Linalool & $5.31-40.00$ & 24.88 & $22.90-27.38$ & $2.34 \pm 0.21$ & 8.12 \\
& Pyrethrum extract* & - & 4.29 & $3.86-4.72$ & - & - \\
\hline \multirow{4}{*}{ TC } & Essential oil & $5.92-30.00$ & 13.45 & $15.31-18.45$ & $4.99 \pm 0.61$ & 17.36 \\
& 1,8-Cineole & $3.95-20.00$ & 12.67 & $11.56-13.79$ & $3.56 \pm 0.31$ & 12.11 \\
& trans-Geraniol & $5.92-30.00$ & 21.34 & $19.44-23.47$ & $2.89 \pm 0.24$ & 0.987 \\
& Linalool & $2.63-20.00$ & 8.12 & $7.43-9.09$ & $3.12 \pm 0.36$ & 12.32 \\
& Pyrethrum extract* & - & 0.36 & $0.32-0.41$ & - & - \\
\hline
\end{tabular}

* Data from Liu et al. (2010).

Table III. Fumigant toxicity of the essential oil of D. japonicus and its main compounds against S. zeamais (SZ) and T. castaneum (TC) adults.

\begin{tabular}{lllcccc}
\hline Insect & Treatment & $\begin{array}{l}\text { Content } \\
(\%)\end{array}$ & $\begin{array}{l}\mathrm{LC}_{50} \\
{[\mathrm{mg} / \mathrm{l} \text { air }]}\end{array}$ & $95 \% \mathrm{FL}$ & Slope $\pm \mathrm{SE}$ & $\begin{array}{l}\text { Chi square } \\
\left(\chi^{2}\right)\end{array}$ \\
\hline \multirow{4}{*}{$\mathrm{SZ}$} & Essential oil & $2.20-18.00$ & 10.11 & $21.99-28.69$ & $2.87 \pm 0.31$ & 15.36 \\
& 1,8-Cineole & $0.95-10.00$ & 2.96 & $2.76-3.21$ & $1.72 \pm 0.15$ & 9.48 \\
& trans-Geraniol & $1.86-15.00$ & 15.11 & $13.85-16.45$ & $4.87 \pm 0.47$ & 14.56 \\
& Linalool & $1.32-10.00$ & 10.02 & $9.01-11.29$ & $2.67 \pm 0.28$ & 12.45 \\
& MeBr* & - & 0.67 & - & - & - \\
\hline \multirow{4}{*}{ TC } & Essential oil & $1.80-20.00$ & 5.26 & $4.74-5.86$ & $2.48 \pm 0.26$ & 8.12 \\
& $1,8-$ Cineole & $1.32-15.00$ & 4.68 & $4.17-5.06$ & $3.14 \pm 0.33$ & 15.85 \\
& trans-Geraniol & $2.60-15.00$ & 14.68 & $13.37-15.64$ & $3.12 \pm 0.41$ & 15.85 \\
& Linalool & $1.32-10.00$ & 9.34 & $8.64-10.17$ & $2.89 \pm 0.32$ & 8.64 \\
& MeBr* & - & 1.75 & - & - & - \\
\hline
\end{tabular}

* From Liu and Ho (1999).

reduce the need for synthetic insecticides and the associated risks. However, for the practical application of the essential oil as novel insecticide/ fumigant, further studies on the safety of the essential oil to humans and on the development of formulations are necessary to improve the efficacy and stability and to reduce costs.

\section{Acknowledgements}

This work was funded by the Hi-Tech Research and Development of China (2011AA10A202). We thank Dr. Q. R. Liu from the College of Life Sciences, Beijing Normal University, Beijing, China for the identification of the investigated plant. 
Adams R. P. (2007), Identification of Essential Oil Components by Gas Chromatography/Mass Spectrometry, $4^{\text {th }}$ ed. Allured Publishing Corporation, Carol Stream, IL, USA.

Arabi F., Moharramipour S., and Sefidkon F. (2008), Chemical composition and insecticidal activity of essential oil from Perovskia abrotanoides (Lamiaceae) against Sitophilus oryzae (Coleoptera: Curculionidae) and Tribolium castaneum (Coleoptera: Tenebrionidae). Int. J. Trop. Insect Sci. 28, 144-150.

Chinese Pharmacopoeia Commission (2010), The Pharmacopoeia of the People's Republic of China. Chemical Industry Press, Beijing, China, Vol. 1, pp. $131-132$.

Chu S.-S., Liu Q.-R., and Liu Z.-L. (2010a), Insecticidal activity and chemical composition of the essential oil of Artemisia vestita from China against Sitophilus zeamais. Biochem. Syst. Ecol. 38, 489-492.

Chu S.-S., Liu S.-L., Jiang G.-H., and Liu Z.-L. (2010b), Composition and toxicity of essential oil of Illicium simonsii Maxim. (Illiciaceae) fruit against the maize weevils. Rec. Nat. Prod. 4, 205-210.

Flora of China Editorial Board (1986), The Flora of China. Sciences Press, Beijing, China, Vol. 73(1), pp. $62-63$.

Isman M.-B. (2006), Botanical insecticides, deterrents, and repellents in modern agriculture and an increasingly regulated world. Annu. Rev. Entomol. 51, $45-66$.

Jiangsu New Medical College (1977), Dictionary of Chinese Herbal Medicine. Shanghai Science \& Technology Press, Shanghai, China, pp. 2267-2269.

Lee B.-H., Annis P.-C., Tumaalii T., and Choi W.-C. (2004), Fumigant toxicity of essential oils from the Myrtaceae family and 1,8-cineole against 3 major stored-grain insects. J. Stored Prod. Res. 40, 553-564.

Li H.-Q., Bai C.-Q., Chu S.-S., Zhou L., Du S.-S., Liu Z.L., and Liu Q.-Z. (2011), Chemical composition and toxicities of the essential oil derived from Kadsura heteroclita stems against Sitophilus zeamais and $M e$ loidogyne incognita. J. Med. Plants Res. 5, 4943-4948.

Liu Z.-L. and Ho S.-H. (1999), Bioactivity of the essential oil extracted from Evodia rutaecarpa Hook. f. et Thomas against the grain storage insects, Sitophilus zeamais Motsch. and Tribolium castaneum (Herbst). J. Stored Prod. Res. 35, 317-328.

Liu Z.-L. and Du S.-S. (2011), Fumigant components from the essential oil of Evodia rutaecarpa Hort unripe fruits. E-J. Chem. 8, 1937-1943.

Liu Z.-L., Liu Q.-R., Chu S.-S., and Jiang G.-H. (2010), Insecticidal activity and chemical composition of the essential oils of Artemisia lavandulaefolia and Artemisia sieversiana from China. Chem. Biodivers. 7, 2040-2045.
Magan N., Hope R., Cairns V., and Aldred D. (2003), Postharvest fungal ecology: impact of fungal growth and mycotoxin accumulation in stored grain. Eur. J. Plant Pathol. 109, 723-730.

Miao Z.-C., Feng R., Zhou Y.-X., and Wei F. (2000a), Chemical structure and NMR of a new saponin from Dipsacus japonicus (Dipsacaceae). Acta Bot. Sin. 42, 421-426.

Miao Z.-C., Zhou Y.-X., Feng R., and Wei F. (2000b), Structural determination of a new bidesmosidic triterpenoid glycoside from Dipsacus japonicus. Chin. J. Org. 20, 81-87.

Mohamed M.-I. and Abdelgaleil S.-A.-M. (2008), Chemical composition and insecticidal potential of essential oils from Egyptian plants against Sitophilus oryzae (L.) (Coleoptera: Curculionidae) and Tribolium castaneum (Herbst) (Coleoptera: Tenebrionidae). Appl. Entomol. Zool. 43, 599-607.

Rajendran S. and Srianjini V. (2008), Plant products as fumigants for stored-product insects control. J. Stored Prod. Res. 44, 126-135.

Sakuma M. (1998), Probit analysis of preference data. Appl. Entomol. Zool. 33, 339-347.

Suthisut D., Fields P.-G., and Chandrapatya A. (2011), Fumigation toxicity of essential oils from three Thai plants (Zingiberaceae) and their major compounds against Sitophilus zeamais and Tribolium castaneum. J. Stored Prod. Res. 47, 222-230.

Trinh T.-T., Tran V.-S., and Adam G. (1999), Study on chemical constituents of Dipsacus japonicus. I. Iridoid and bis-iridoid glycosides. Vietnam J. Chem. 37, 64-69.

Trinh T.-T., Tran V.-S., and Adam G. (2002), Study on chemical constituents of Dipsacus japonicus. II. Triterpene glycosides. Vietnam J. Chem. 40, 13-19.

Tripathi A.-K., Prajapati V., Aggarwal K.-K., and Kumar S. (2001), Toxicity, feeding deterrence, and effect of activity of 1,8-cineole from Artemisia annua on progeny production of Tribolium castaneum (Coleoptera: Tenebrionidae). J. Econ. Entomol. 94, 979-983.

Wei F., Lou Z. C., Gao M., and Miao Z. C. (1995), Application of new techniques of NMR in structure elucidation of japondipsaponin $\mathrm{E}_{1}$ isolated form Dipsacus japonicus Miq. Acta Pharm. Sin. 30, 831-837.

Wei F., Liu L.-M., and Lou Z.-C. (1998), Application of new techniques of NMR in structure elucidation of japondipsaponin $\mathrm{E}_{2}$ isolated form Dipsacus japonicus Miq. J. Shenyang Pharm. Univ. 15, 120-124.

Zapata N. and Smagghe G. (2010), Repellency and toxicity of essential oils from the leaves and bark of Laurelia sempervirens and Drimys winteri against Tribolium castaneum. Ind. Crops Prod. 32, 405-410.

Zettler J.-L. and Arthur F.-H. (2000), Chemical control of stored product insects with fumigants and residual treatments. Crop Prot. 19, 577-582. 